This Section of Epidemiology and Psychiatric Sciences appears in each issue of the Journal to stress the relevance of epidemiology for behavioral neurosciences, reporting the results of studies that explore the use of an epidemiological approach to provide a better understanding of the neural basis of major psychiatric disorders and, in turn, the utilisation of the behavioural neurosciences for promoting innovative epidemiological research.

The ultimate aim is to help the translation of most relevant research findings into every-day clinical practice. These contributions are written in house by the journal's editorial team or commissioned by the Section Editor (no more than 1000 words, short unstructured abstract, 4 key-words, one Table or Figure and up to ten references).

Paolo Brambilla, Section Editor

\title{
The association between the serotonin and dopamine neurotransmitters and personality traits
}

\author{
G. Delvecchio ${ }^{1}$, M. Bellani ${ }^{2 *}$, A. C. Altamura ${ }^{3}$ and P. Brambilla ${ }^{3,4 *}$ \\ ${ }^{1}$ IRCCS 'E. Medea' Scientific Institute, Bosisio Parini, Italy \\ ${ }^{2}$ Department of Public Health and Community Medicine, Inter University Centre for Behavioural Neurosciences, University of Verona, Verona, \\ Italy \\ ${ }^{3}$ Department of Neurosciences and Mental Health, Fondazione IRCCS Ca' Granda Ospedale Maggiore Policlinico, University of Milan, Milan, Italy \\ ${ }^{4}$ Department of Psychiatry and Behavioural Neurosciences, University of Texas at Houston, TX, USA
}

Evidence from previous studies has reported that complex traits, including psychiatric disorders, are moderately to highly heritable. Moreover, it has also been shown that specific personality traits may increase the risk to develop mental illnesses. Therefore the focus of the research shifted towards the identification of the biological mechanisms underpinning these traits by exploring the effects of a constellation of genetic polymorphisms in healthy subjects. Indeed, studying the effect of genetic variants in normal personality provides a unique means for identifying candidate genes which may increase the risk for psychiatric disorders. In this review, we discuss the impact of two of the most frequently studied genetic polymorphisms on personality in healthy subjects, the 5-HTT polymorphism of the serotonin transporter and the DRD2/DRD4 polymorphisms of the D2/D4 dopamine's receptors. The main aims are: (a) to highlight that the study of candidate genes provides a fruitful ground for the identification of the biological underpinnings of personality without, though, reaching a general consensus about the strength of this relationship; and (b) to outline that the research in personality genetics should be expanded to provide a clearer picture of the heritability of personality traits.

Received 29 October 2015; Accepted 12 December 2015; First published online 11 January 2016

Key words: Attitudes, biological markers, neurophysiology, risk factors.

The investigation of the biological bases of personality has been an object of study for a long time. Specifically, inter-individual variations in personality traits have

* Address for correspondence: Dr M. Bellani, Department of Public Health and Community Medicine, University of Verona, Piazzale L.A. Scuro 10, 37134 Verona, Italy; Professor P. Brambilla, Department of Neurosciences and Mental Health, Fondazione IRCCS Ca' Granda Ospedale Maggiore Policlinico, via F. Sforza 35, 20122 Milan, Italy.

(Email: marcella.bellani@univr.it; paolo.brambilla1@unimi.it) been considered highly heritable and therefore associated with the action of specific neurotransmitters which are, in turn, regulated by a biological constellation of genes and their polymorphic variants (Cloninger et al. 1994). Although there is a variety of questionnaires used for exploring the personality's profile of individuals, the Temperament and Character Inventory (Cloninger et al. 1994) is the most widely used and validated scale employed for identifying the biological underpinning of personality 
(Comings et al. 2000; Brändström et al. 2001). This psychobiological model of personality identified seven clusters that can be subdivided in four dimensions of temperament - Harm Avoidance, Novelty Seeking, Reward Dependence and Persistence - and three dimensions of character - Self-Directedness, Cooperativeness and Self-Transcendence. Cloninger's theory of the inter-relation between neurotransmitters and personality traits has opened a new field of investigation exploring the impact of specific genetic polymorphisms on personality and therefore on human behaviour. So far, the research in this field explored the effect of the (1) dopamine, linked to Novelty Seeking and with the 'system of behavioural activation'; (2) serotonin, related to Harm Avoidance and with the 'system of behavioural inhibition'; and (3) noradrenalin, associated with Reward Dependence (Comings et al. 2000). The majority of personality genetics studies based their investigation on the impact of genetic polymorphisms known to regulate the action of serotonin transporter (5-HTT) and dopamine's receptors (DRD2 and DRD4) in both patients and healthy subjects. Therefore, we here specifically focus on serotonin and dopamine.

The 5-HTT is a functional polymorphism within the promoter sequence of the serotonin transporter gene and it is involved in a variety of processes, including impulsivity, suicidal ideation, mood and anxiety. Moreover, the presence of the short allele of this polymorphism (s-allele) was associated with major depression, anxiety and schizophrenia (Kuzelova et al. 2010). Similarly, the DRD2 and DRD4 are functional polymorphisms that regulate the expression of the dopamine D2 and D4 receptors, which are important in modulating reward, locomotion and learning. The low-frequent alleles within these polymorphisms are also linked to schizophrenia, depression and drug addiction (Missale et al. 1998). However, although the effects of these genes on psychopathology have been explored, there is not a general consensus about the strength and nature of the relationship between the serotonin and dopamine activity and personality traits in healthy subjects.

The importance of studying the role of genetic variants on human personality is evident especially because it might inform us on the traits that are more predictive of risk of psychiatric illnesses. With regard to the 5-HTT polymorphism, the majority of the studies on healthy subjects found significant associations with anxiety-traits, such as Harm Avoidance (Van Gestel \& Van Broeckhoven, 2003). These findings are in line with the neurobiological basis of depression and anxiety which has been linked to the mechanism of action of serotonergic antidepressant medications. The first study that paved the way for the identification of the association between serotonin and personality traits was published in 1996 by Lesch et al. showing that carriers of the short allele of the 5-HTT polymorphism had higher Harm Avoidance. On the other hand, the DRD2 and DRD4 polymorphisms have been found to be associated with Novelty Seeking, which is linked with exploratory excitability and impulsivity (Ebstein et al. 1996; Noble et al. 1998) (see Table 1 for a selection of studies exploring the association between the serotonin and dopamine neurotransmitters and personality). This association is consistent with previous findings which reported the role of the dopamine in mediating exploratory behaviours in animal models as well as in emotion and cognition (Benjamin et al. 1996). Interestingly, a recent review also reported a significant association between dopamine and the schizophrenia spectrum, including the schizotypal personality disorder (Mohr \& Ettinger, 2014). This evidence further supports the importance of exploring the neurobiological bases not only of severe chronic disorders, but also of psychiatric spectra which include personality disorders as well as subjects with increased genetic and clinical risk for a specific illness. However, it is important to highlight the existence of some negative studies which found no association with these personality dimensions (Herbst et al. 2000; Gebhardt et al. 2004) as well as studies reporting contrasting results, with the same genetic variant associated with higher and lower scores in the same personality scale (van Gestel \& Van Broeckhoven, 2003). In addition, there is increase evidence of the association between the 5-HTT and DRD2/DRD4 polymorphisms with character dimensions which, according to Cloninger's Theory, are acquired during the development through socio-cultural learning and not as genetically determined as the temperament dimensions (Cloninger et al. 1994). Studies from different cultural populations reported that healthy subjects carriers of the short allele within the 5-HTT showed lower scores in all the Cloninger's character dimensions, including Self-Transcendence (Ham et al. 2004), Self-Directedness (Gonda et al. 2009; Saiz et al. 2010; Calati et al. 2014) and Cooperativeness (PełkaWysiecka et al. 2012). Similarly, for the DRD2 polymorphism, Tsuchimine et al. (2012) found that the less frequent allele was associated with significant lower scores in the Self-Directedness scale (Table 1). This biological evidence further supports the findings from independent twin studies, which supported a similar heritability for temperament and character dimensions (Al-Halabí et al. 2011; Brambilla et al. 2014; Picardi et al. 2015).

In conclusion, these findings point to two new avenues of enquiry in relation to personality traits. First, 
Table 1. Selection of studies investigating the association between serotonin and dopamine neurotransmitters and personality in healthy subjects

\begin{tabular}{|c|c|c|c|}
\hline Study & $\begin{array}{l}\text { Number of } \\
\text { subjects }\end{array}$ & Polymorphism & Findings \\
\hline \multicolumn{4}{|l|}{ Serotonin } \\
\hline Lesch et al. (1996) & 505 & 5-HTT & 5-HTT (s-allele) associated with higher Harm Avoidance \\
\hline Herbst et al. (2000) & 587 & 5-HTT & No association between 5-HTT and Harm-Avoidance \\
\hline Ham et al. (2004) & 147 & 5-HTT & 5-HTT polymorphisms associated with Self-Transcendence \\
\hline Gonda et al. (2009) & 169 & 5-HTT & 5-HTT (s-allele) associated with lower Self-Directedness \\
\hline Saiz et al. (2010) & 404 & $5-\mathrm{HTT}$ & 5-HTT (s-allele) associated with lower Self-Directedness \\
\hline Pełka-Wysiecka et al. (2012) & 406 & $5-\mathrm{HTT}$ & 5-HTT (s-allele) associated with lower Cooperativeness \\
\hline \multicolumn{4}{|l|}{ Dopamine } \\
\hline Ono et al. (1997) & 153 & DRD4 & $\begin{array}{l}\text { Long alleles of the polymorphic exon III repeat sequence of } \\
\text { DRD4 associated with Novelty Seeking }\end{array}$ \\
\hline Noble et al. (1998) & 119 & DRD2 & $\begin{array}{l}\text { DRD2 less frequent allele associated with higher Novelty } \\
\text { Seeking }\end{array}$ \\
\hline Gebhardt et al. (2004) & 109 & $\begin{array}{l}\text { DRD2 } \\
\text { DRD4 }\end{array}$ & $\begin{array}{l}\text { No significant association of DRD2 and DRD4 genes with } \\
\text { personality traits }\end{array}$ \\
\hline Lee et al. (2003) & 243 & $\begin{array}{l}\text { DRD4 } \\
\text { DRD2 }\end{array}$ & $\begin{array}{l}\text { DRD4 gene associated with Novelty Seeking in females. } \\
\text { Females with DRD2 less frequent alleles (-141C Ins/Ins } \\
\text { genotype) associated with higher Reward Dependence }\end{array}$ \\
\hline Tsuchimine et al. (2012) & 1084 & DRD2 & $\begin{array}{l}\text { DRD2 gene associated with Self-Directedness. Men with less } \\
\text { frequent allele (-141 -Ins/Ins genotype) associated with } \\
\text { lower Self-Directedness compared to males with -141C } \\
\text { Ins/Del alleles. }\end{array}$ \\
\hline
\end{tabular}

the results from the personality genetics studies, together with previous evidence from family and twin studies reporting heritability estimates of personality traits, further suggest that genes play a greater role in shaping all aspects of personality, including both character and temperament dimensions. Second, although the study of specific candidate genes brought compelling findings, the lack of consistency underscores the need for a more detailed examination of the role of genetic variants on personality traits. Indeed, the success of the future genetics personality research in identifying genetic factors might be linked to (a) the employment of larger sample size which may overcome the limitations of the current studies characterised by small sample size and therefore with low explanatory power; (b) the investigation of multiple genetic variants, especially because complex traits are characterised by pleiotropy and polygeneity (Plomin et al. \& Deary, 2015); and (c) the differentiation of the sample according to the age and sex of the participants which have been reported to significantly influence personality scales (Fresán et al. 2011).

\section{Acknowledgement}

None.

\section{Financial Support}

Dr Brambilla and Dr Bellani were partly supported by the Italian Ministry of Health (RF-2011-02352308 to Dr Brambilla and GR-2010-2319022 to Dr Bellani) and by the BIAL Foundation to Dr Brambilla (Fellowship no. 262/12).

\section{Conflict of Interest}

None.

\section{Ethical Standard}

The authors declare that no human or animal experimentation was conducted for this work.

\section{References}

Al-Halabí S, Herrero R, Sáiz PA, García-Portilla MP, Errasti JM, Corcoran (2011). A cross-cultural comparison between Spain and the USA: temperament and character distribution by sex and age. Psychiatry Research 186, 397-401.

Benjamin J, Li L, Patterson C, Greenberg BD, Murphy DL, Hamer DH (1996). Population and familial association 
between the D4 dopamine receptor gene and measures of novelty seeking. Nature Genetics 12, 81-84.

Brambilla P, Fagnani C, Cecchetto F, Medda E, Bellani M, Salemi M, Picardi A, Stazi MA (2014). Genetic and environmental bases of the interplay between magical ideation and personality. Psychiatry Research 215, 453-459.

Brändström S, Richter J, Przybeck T (2001). Distributions by age and sex of the dimensions of Temperament and Character Inventory in a crosscultural perspective among Sweden, Germany, and the USA. Psychological Reports 89, 747-758.

Calati R, Signorelli MS, Gressier F, Bianchini O, Porcelli S, Comings DE, De Girolamo G, Aguglia E, MacMurray J, Serretti A (2014). Modulation of a number of genes on personality traits in a sample of healthy subjects. Neuroscience Letters 566, 320-325.

Cloninger CR, Przybeck TR, Svrakic DM, Wetzel RD (1994). The Temperament and Character Inventory (TCI): a Guide to its Development and Use. Center for Psychobiology of Personality, Washington University: St. Louis, MO.

Comings D, Gade-Andavolu R, Gonzalez N, Wu S, Muhleman D, Blake H (2000). A multi-variate analysis of 59 candidate genes in personality traits: the temperament and character inventory. Clinical Genetics 58, 375-385.

Ebstein RP, Novick O, Umansky R, Priel B, Osher Y, Blaine D (1996). Dopamine D4 receptor (D4DR) exon III polymorphism associated with the human personality trait of Novelty Seeking. Nature Genetics 12, 78-80.

Fresán A, Robles-García R, López-Avila A, Cloninger CR (2011). Personality differences according to age and sex in a Mexican sample using the Temperament and Character Inventory-Revised. Comprehensive Psychiatry 52, 774-779.

Gebhardt C, Leisch F, Schüssler P, Fuchs K, Stompe T, Sieghart W, Hornik K, Kasper S, Aschauer HN (2004). Non-association of dopamine D4 and D2 receptor genes with personality in healthy individuals. American Journal of Medical Genetics Part B, Neuropsychiatric Genetics 126B, 106-110.

Gonda X, Fountoulakis KN, Juhasz G, Rihmer Z, Lazary J, Laszik A, Akiskal HS, Bagdy G (2009). Association of the s allele of the 5-HTTLPR with neuroticism-related traits and temperaments in a psychiatrically healthy population.

European Archives of Psychiatry and Clinical Neuroscience 259, 106-113.

Ham BJ, Kim YH, Choi MJ, Cha JH, Choi YK, Lee MS (2004). Serotonergic genes and personality traits in the Korean population. Neuroscience Letters 354, 2-5.

Herbst JH, Zonderman AB, McCrae RR, Costa PT (2000). Do the dimensions of the temperament and character inventory map a simple genetic architecture? Evidence from molecular genetics and factor analysis. American Journal of Psychiatry 157, 1285-1290.

Kuzelova H, Ptacek R, Macek M (2010). The serotonin transporter gene (5-HTT) variant and psychiatric disorders: review of current literature. Neuroendocrinology Letters 31, 4-10.

Lee HJ, Lee HS, Kim YK, Kim L, Lee MS, Jung IK, Suh KY, Kim S (2003). D2 and D4 dopamine receptor gene polymorphisms and personality traits in a young Korean population. American Journal of Medical Genetics Part B, Neuropsychiatric Genetics 121B, 44-49.

Lesch K-P, Bengel D, Heils A, Sabol SZ, Greenberg BD, Petri S (1996). Association of anxiety-related traits with a polymorphism in the serotonin transporter gene regulatory region. Science 274, 1527-1531.

Missale C, Nash SR, Robinson SW, Jaber M, Caron MG (1998). Dopamine receptors: from structure to function. Physiological Review 78, 189-225.

Mohr C, Ettinger U (2014). An overview of the association between schizotypy and dopamine. Frontiers in Psychiatry 5, 184.

Noble EP, Ozkaragoz TZ, Ritchie TL, Zhang X, Belin TR, Sparkes RS (1998). D2 and D4 dopamine receptor polymorphisms and personality. American Journal of Medical Genetics: Neuropsychiatric Genetics 81, 257-267.

Ono Y, Manki H, Yoshimura K, Muramatsu T, Mizushima H, Higuchi S, Yagi G, Kanba S, Asai M (1997). Association between dopamine D4 receptor (D4DR) exon III polymorphism and novelty seeking in Japanese subjects. American Journal of Medical Genetics 74, 501-503.

Pełka-Wysiecka J, Ziętek J, Grzywacz A, Kucharska-Mazur J, Bienkowski P, Samochowiec J (2012). Association of genetic polymorphisms with personality profile in individuals without psychiatric disorders. Progress in Neuro-Psychopharmacology and Biological Psychiatry 39, 40-46.

Picardi A, Fagnani C, Medda E, Toccaceli V, Brambilla P, Stazi MA (2015). Genetic and environmental influences underlying the relationship between autistic traits and temperament and character dimensions in adulthood. Comprehensive Psychiatry 58, 178-188.

Plomin R, Deary IJ (2015). Genetics and intelligence differences: five special findings. Molecular Psychiatry 20, 98-108.

Saiz PA, Garcia-Portilla MP, Herrero R, Arango C, Corcoran P, Morales B, Bascarán MT, Alvarez V, Coto E, Paredes B, Fernández JM, Bobes J (2010). Interactions between functional serotonergic polymorphisms and demographic factors influence personality traits in healthy Spanish Caucasians. Psychiatry Genetics 20, 171-178.

Tsuchimine S, Yasui-Furukori N, Sasaki K, Kaneda A, Sugawara N, Yoshida S, Kaneko S (2012). Association between the dopamine D2 receptor (DRD2) polymorphism and the personality traits of healthy Japanese participants. Progress in Neuro-Psychopharmacology and Biological Psychiatry 38, 190-193.

Van Gestel S, Van Broeckhoven C (2003). Genetics of personality: are we making progress? Molecular Psychiatry 8, 840-852. 